\title{
MICHEL ROCHEFORT E O INSTITUTO BRASILEIRO DE GEOGRAFIA E ESTATÍSTICA NA DÉCADA DE 1960
}

\author{
Michel Rochefort and the Brazilian Institute of Geography and Statitics (IBGE) in the 1960s
}

\author{
Paulo Roberto de Albuquerque Bomfim \\ Instituto Federal de Educação, Ciência e Tecnologia de São Paulo IFSP \\ albuquerquebomfim@hotmail.com
}

Artigo recebido em 12/01/2015 e aceito para publicação em 16/11/2015

RESUMO: O geógrafo francês Michel Rochefort (1927-2015) construiu sua trajetória como importante nome do planejamento em seu país. Prova disso é sua longa participação no Comissariat Général du Plan [Escritório Geral de Planejamento], órgão do governo da França, cujos objetivos em muito se assemelhavam aos do Instituto Brasileiro de Geografia e Estatística, instituição que será um dos pontos nodais de uma relação de Rochefort estabelecida com o Brasil ao longo de cinco décadas. Desse contato do autor com o Brasil, analisar-se-á tão somente a década de 1960, quando o IBGE, municiado das metodologias propostas por Rochefort e por François Perroux, elaborou importantes políticas de subsídios ao planejamento. A despeito das limitações teóricas contidas nos trabalhos do IBGE da década de 1960, as contribuições do Instituto revelaram-se de grande importância para as políticas territoriais ao menos nas duas décadas subsequentes. E Michel Rochefort certamente exemplifica, por meio de sua obra, a inconteste contribuição da geografia francesa para a geografia brasileira nos anos marcados pelo desenvolvimentismo e pelo planejamento como ideia-força.

Palavras-chave: História do Pensamento Geográfico; IBGE; Michel Rochefort; Planejamento; Regionalização no Brasil.

ABSTRACT: French geographer, Michael Rochefort (1927-2015), built his career as an important name in the planning of his country. Part of this was because of his lengthy participation in the Comissariat General du Plan, a governmental agency in France, whose objectives are quite similar to the Brazilian Institute of Geography and Statistics (IBGE), an institution which would be one of the nodal points in Rochefort's relationship with Brazil for over five decades. This article analyses this relationship in the 1960s, when IBGE, together with the methodologies proposed by Rochefort and François Perroux, developed important subsidy policies for planning. Despite the theoretical limitations in IBGE's work in the 1960s, the institute's work turned out to be of great importance for the political territories in at least the two decades following. Michael Rochefort exemplifies, through his work, the undeniable contribution of French geography to Brazilian geography during the years marked by the period of planning and national developmentalism in Brazil. Keywords: History of Geographical Thought; IBGE; Michel Rochefort; Planning; Regionalization in Brazil. 


\section{INTRODUÇÃO}

O dia 07 de janeiro de 2015 foi trágico para os parisienses. $\mathrm{O}$ atentado ao Charlie Hebdo, sem aqui entrar em detalhes, chocou a todos. Na mesma cidade, naquele mesmo dia, falecia, aos 88 anos, Michel Rochefort.

Longevo, nascido em 01 de janeiro de 1927, o professor Michel Rochefort estabeleceu uma longa relação com a geografia brasileira e o Brasil. Um namoro de cinquenta anos, conforme esse importante geógrafo salientou em sua fala num encontro acadêmico no Brasil (PUC CAMPINAS, 2006). Essas cinco décadas de colaboração com a geografia brasileira iniciaram-se no emblemático XVIII Congresso Internacional de Geografia, ocorrido no Rio de Janeiro, em 1956. Daí o objetivo deste breve texto: apresentar uma visão geral a respeito da influência do Professor Michel Rochefort na geografia brasileira na década de 1960, em especial em relação a seu trabalho desenvolvido no Instituto Brasileiro de Geografia e Estatística (IBGE).

\section{A QUESTÃO URBANA NO BRASIL E A PARTICIPAÇÃO DE ROCHEFORT}

Oitavo congresso promovido pela União Geográfica Internacional (fundada em Bruxelas em 1922) - os anteriores foram os do Cairo (1925), Cambridge (1928), Paris (1931), Varsóvia (1934), Amsterdam (1938), Lisboa (1949) e Washington (1952) - e décimo oitavo encontro internacional (anteriormente à UGI os geógrafos se reuniram em congressos internacionais em Antuérpia - 1871, Paris - 1875, Veneza - 1881, Paris - 1889, Berna - 1891, Londres - 1895, Berlim - 1899, Washington - 1904, Genebra - 1908 - e Roma - 1913 [ROBIC, 1996, p.14]), o Congresso do Rio de Janeiro foi articulado a partir do encontro de Washington, quando se constituiu um novo comitê executivo para o quadriênio 1952-1956, tendo como nomes mais importantes o britânico Dudley Stamp (um nome de grande relevo da chamada "geografia aplicada"), o francês Max Sorre, o português Orlando Ribeiro e o brasileiro Hilgard O’Reilly Sternberg (1917-2011), primeiro geógrafo formado pela Universidade do Brasil a tornar-se docente da mesma casa.

O XVIII Congresso, realizado em paralelo à Exposição Geográfica e Cartográfica entre os dias 08 e 19 de agosto de 1956, na Escola Naval, no Rio de Janeiro, contou com 270 comunicações e 1220 inscrições, entre aquelas individuais e as institucionais. AAssociação dos Geógrafos Brasileiros (AGB) e o Conselho Nacional de Geografia (ao qual se uniu o Conselho Nacional de Estatística para a conformação do IBGE, em 26/01/1938) estavam entre as instituições nacionais à frente do Congresso, o qual também contou com verbas do Centro Cultural Brasil-Israel, Fundação Rockfeller, Coordenação de Aperfeiçoamento de Pessoal de Nível Superior (CAPES), Ministério do Exterior, USP (por meio de Aroldo de Azevedo) e da prefeitura do Distrito Federal, além do Centro de Pesquisa em Geografia do Brasil (CPGB), por sua vez, apoiado financeiramente pela Standard Oil e locus chave da atuação de Hilgard Sternberg (MACHADO, 2002, p.122; UGI, 1959).

A França particularmente enviou uma delegação repleta de geógrafos, cujas trajetórias então já eram sobejamente conhecidas (Jacqueline BeaujeuGarnier, Pierre Deffontaines, Pierre George, Pierre Monbeig, Maximillien Sorre, só para citar alguns) ou cujos trabalhos repercutiriam nos anos subsequentes ao XVIII Congresso, caso de Michel Rochefort.

A "Geografia Aplicada" teve grande importância no Congresso, num contexto nacionaldesenvolvimentista, de intervenção estatal na economia e confiança no planejamento, quando a questão urbana e o debate teórico sobre as mudanças na definição e na delimitação regional do Brasil começavam a se tornar tópicos de grande centralidade no IBGE. Nesse tom, Rochefort, professor da Universidade de Estrasburgo, apresentava uma comunicação ao Congresso (cujos anais foram publicados em 1959), acentuando fortemente a temática da rede urbana de uma região - tema de excelência no IBGE nos anos de 1960 e 1970 -, para o autor, compreendida como a combinação de certo número e "tipos" de cidades que manteriam entre si uma relação de interpendência. Em suas palavras,

Esses tipos são determinados não somente 
pelas funções atuais das cidades, mas por sua posição e sua estrutura, que refletem sua história. Nessas condições, a unidade de comparação, no interior de uma série maior considerada, não é mais a cidade, mas a rede urbana regional, definida, nos limites regionais de influência da cidademetrópole, pela existência e pela localização de um certo número de tipos de cidades que servem [...] como suporte para a atividade industrial regional (ROCHEFORT, 1959, p.427. Tradução nossa).

Como consequência imediata do Congresso Internacional, deram-se os cursos intitulados Altos Estudos Geográficos, ministrados por Hilgard Sternberg, no Departamento de Geografia da Faculdade Nacional de Filosofia e contando com a participação de Pierre Deffontaines, Pierre Monbeig, André Cailleux e Carl Troll (MACHADO, 2002, p.103-104).

Em 04 de abril de 1957, Rochefort ministrava uma conferência na AGB do Rio de Janeiro, da qual resultou uma breve comunicação escrita por Pedro Pinchas Geiger no Boletim Carioca de Geografia, em que se destaca a proposição de Rochefort alçada à condição de verdadeiro "método". A transcrição é longa, mas sintetiza uma concepção sobre estudo de redes urbanas, desde então, utilizada amplamente em artigos da Revista Brasileira de Geografia (do IBGE) e como instrumento para o planejamento regional, política pública que estaria no cerne das investidas do Ministério do Planejamento a partir do golpe militar de 1964. Ironicamente, Rochefort e outros pares ligados à chamada "Geografia Ativa" haviam sido militantes do Partido Comunista Francês, porém, numa hipótese aqui aventada, o próprio nacionaldesenvolvimentismo e todos seus elaboradores, no Brasil, na França e em outros países, acreditavam na "correção", a cargo do Estado, das desigualdades regionais, realizada por meio da penetração da industrialização e dos polos "modernos" da economia, de maneira a paulatinamente superar e vencer o "atraso", postura que pareceria estar acima de qualquer ambiente político-institucional.
Visando a obter uma primeira apreciação da situação hierárquica dos centros urbanos de uma rêde [sic] em estudo, o método [de Rochefort] utiliza os dados estatísticos da "composição da população ativa segundo os ramos das profissões", visto que nestes números se refletem as funções dos centros urbanos. Êle [sic] tem por base o chamado setor ternário $(\mathrm{t})$ da população ativa de uma cidade, que engloba o comércio, os serviços e a administração, e que exprime a função de relação da cidade, isto é, o seu papel em prestar serviços à área circunvizinha [...] A relação entre a quantidade da população ativa do setor ternário e a quantidade total da população ativa será o primeiro elemento para a medição da importância de um centro urbano (GEIGER, 1957, p.5).

Nos primeiros tempos de sua colaboração mais direta com o IBGE, Rochefort constitui um profícuo contato (e uma longa amizade) com Milton Santos (1926-2001) que acabara de voltar justamente de Estrasburgo. Santos foi um dos fundadores do Laboratório de Geomorfologia e Estudos Regionais da Universidade da Bahia, onde, na mesma época, vários professores franceses ministraram cursos ou palestras, como Pierre Monbeig, Jean Tricart, Jacqueline Beaujeu-Garnier, Pierre George, Nicole Lacroix e Pierre Deffontaines. Na ocasião, março de 1960, Rochefort proferiu algumas palestras sobre a) o conceito de complexo agrário; b) os critérios de classificação dos centros industriais; c) a organização de centros de serviços regionais (CORREIA FILHO, 1962).

Por iniciativa de Milton Santos e sob os auspícios da Embaixada da França (em convênio com o CNG), nosso autor lecionará nos anos de 196061 entre a Universidade da Bahia e a Universidade de Pernambuco, num contexto em que, durante o governo Jânio Quadros, optava-se por uma política descentralizada de planejamento, a qual daria maior peso a iniciativas "federativas" de política regional, a exemplo da Comissão Interestadual da Bacia do Paraná-Uruguai (PONTES, 1983). Nessa fase de contato de Rochefort com o Brasil, a partir do 
Nordeste, é possível ainda destacar outras atividades, como o Curso em Geografia Humana e Geografia Urbana (Universidade de Pernambuco, $1^{\circ}$ semestre de 1960), de Geografia Humana ( $2^{\circ}$ semestre de 1960) ou a conferência "O papel da geografia na Unidade das Ciências do Homem" (Recife, março de 1961). (CORREIA FILHO, 1962; NOTICIÁRIO, 1963).

Já no Conselho Nacional de Geografia (CNG), Rochefort torna-se o encarregado de coordenar a partir de 1960 três grandes projetos de pesquisa: o Potencial Humano, Geografia Industrial e Geografia Urbana. No âmbito desses projetos, destaca-se o Grupo de Geografia da População da Divisão de Geografia do CNG, orientado pelo geógrafo francês e, no caso, coordenado pela ibegeana Ruth Magnanini. Durante os governos Quadros e Goulart, iniciavase o grande projeto do IBGE visando a uma nova regionalização do Brasil. Escolar e Moraes (1991) recordam o quanto a geografia francesa daqueles anos representava uma exacerbação das propostas "tradicionais", resultando em uma intenção "Ativa", na qual ressaltava - tendo como metodologia o tratamento de dados quantitativos e a tabulação dos mesmos em cartogramas - uma preocupação central na atividade econômica, advogando-se o planejamento como grande instrumento interventor no território. Nos trabalhos do Grupo de Geografia da População, afinado à "nova metodologia da Geografia", abordavam-se diversos aspectos da população brasileira, tomando como exemplo o Nordeste e a antiga Região Leste (O Leste Setentrional, no caso, Bahia e Sergipe) como laboratórios para uma futura extensão desses estudos para todo o território nacional (MAGNANINI, 1962).

Os estudos realizados dentro do espírito da "nova metodologia" de Rochefort não abandonavam a velha leitura do Nordeste como região-problema: se desta vez não mais a seca era o grande obstáculo ao desenvolvimento, a população desigualmente distribuída, a agricultura não planejada e a indústria e serviços de baixo padrão tecnológico punham-se como entraves à superação do subdesenvolvimento. Haveria de se romper com os ciclos viciosos da pobreza, por meio de uma noção de "causação circular"; central na construção de uma teoria do desenvolvimento (e do subdesenvolvimento). Em suma, em oposição aos "efeitos regressivos" (quando os mercados de regiões pobres se tornavam dependentes das regiões mais industrializadas de um país) haveria certos efeitos propulsores "que se [propagariam] do centro de expansão econômica para outras regiões" (MYRDAL, 1965, p.58). A estratégia de planejamento consistiria em voltar essa produção ao abastecimento de indústrias em desenvolvimento, que, se tivessem mão-de-obra suficiente, poderiam gerar efeitos de indústria de bens de consumo. Nas páginas da RBG lia-se que:

A promoção de novas indústrias em núcleos urbanos do interior e o desenvolvimento dos serviços, auxiliando na absorção da mão-de-obra excedente, seriam fatôres [sic] de diminuição do êxodo [populacional do Nordeste] - isso sem descurar da agricultura que, melhor cuidada, também ofereceria maiores possibilidades de trabalho. (GRUPO DE GEOGRAFIA DA POPULAÇÃO DA DIVISÃO DE GEOGRAFIA [IBGE], 1965, p.164)

Importante lembrar que, após uma estadia no Brasil entre 1960 e 1962, Rochefort não deixaria de frequentar a ponte área França Brasil, trabalhando diretamente, naquilo que se poderia classificar com uma $1^{\text {a }}$ fase de sua presença por estas terras, em duas importantes produções ibegeanas, marcadas inequivocamente pelas suas proposições, a saber: Evolução da rêde urbana brasileira (GEIGER, 1963) e O Rio de Janeiro e sua região (BERNARDES, 1964). Neste último, Lysia Bernardes estudou o conceito de região urbana, utilizando como critério para defini-la a extensão espacial dos vários ramos do setor de serviços, com o escopo de identificar a área de influência dominante da antiga capital federal e as áreas de competição entre o Rio e as capitais regionais do estado - algo, fundamental para o estabelecimento das micro e mesorregiões do IBGE.

Quando Rochefort retorna para nova temporada no Brasil, numa $2^{\text {a }}$ fase, entre 1967 e 1968, os ventos no país eram outros. O golpe militar e a consolidação da modernização conversadora reforçavam o papel intervencionista do Estado. O IBGE não ficaria imune aos esbirros do Estado. O general Aguinaldo José 
Senna Campos torna-se presidente da instituição (entre 1964 e 1967), numa "transição" que quase levaria o Instituto a desaparecer, fundindo-se ao então recémcriado EPEA (Escritório de Pesquisa Econômica Aplicada - atual IPEA, Instituto de Pesquisa Econômica Aplicada). Se não houve a pretendida fusão, agora ambos os órgãos passavam a subordinarse ao Ministério do Planejamento, reestruturado em 1964, já que anteriormente tivera breve vida como pasta "extraordinária", sob responsabilidade de Celso Furtado. O novo ministério, capitaneado por Roberto Campos, tinha como objetivo central para a ciência geográfica a ênfase em seu caráter "aplicado", supostamente fundamental para o êxito dos novos critérios de regionalização do Brasil (IBGE, 1967; 1968), os quais foram essenciais para as políticas territoriais que estariam nos anos seguintes contidas no I e II Plano Nacional de Desenvolvimento (BRASIL, 1971; 1974). Na nova estrutura do IBGE e,

De acordo com o Estatuto, aprovado por decreto presidencial em 2 de agosto de 1967, regulamentando, assim, o Decreto-Lei $\mathrm{n}^{\circ}$ 161, de 13 de fevereiro de 1967, institui-se a Fundação IBGE, dividida entre órgãos como o Conselho Diretor, a Presidência, os Órgãos Autônomos (Instituto Brasileiro de Geografia, Instituto Brasileiro de Estatística e Escola Nacional de Ciências Estatísticas) e o Conselho Fiscal. O Conselho Diretor previa a seguinte composição: Presidente da Fundação (simultaneamente, Presidente do Conselho), Diretores Superintendentes de Órgãos Autônomos, Representante do Ministério do Interior, Representante do Ministério do Planejamento e Coordenação Geral e, por fim, um Representante do Estado Maior das Forças Armadas (EMFA). (IBGE, 1967, p.119).

Esse ambiente político-institucional corresponde a uma fase do IBGE na qual Lysia Bernardes torna-se uma figura central no novo Departamento de Geografia do IBG - Instituto Brasileiro de Geografia -, ao mesmo tempo em que o crescimento do IPEA e as intenções de Planejamento do Estado coadunam-se ao objetivo central de propor uma nova regionalização do Brasil (a primeira é de 1942), cujos fundamentos teóricos fincaram-se em duas referências principais: a teoria dos polos de desenvolvimento de François Perroux e a metodologia de redes urbanas, de Rochefort.

Falemos uma breve linha sobre a teoria dos polos de desenvolvimento: seu cerne seria a concepção segundo a qual o crescimento não surgiria por toda parte de uma só vez. Manifestava-se, ao invés, com intensidade variável em pontos ou polos que se expandiriam pelo conjunto da economia por meio de determinados canais (BOUDEVILLE, 1972, p.112): os eixos de desenvolvimento, cuja armadura, contendo vias de transportes e conjuntos complexos de atividades, faria da Nação uma constelação de polos com seus meios de propagação, estruturada economicamente pela combinação de unidades motrizes (indústrias) (PERROUX, 1967, p.208).

Em exposição feita no EPEA, Rochefort (1967) apontava as condições ideais para a planificação (à maneira dos "países desenvolvidos"); observando, e aqui está o ponto nodal desse texto, as fragilidades do trabalho então recém-elaborado pelo $\mathrm{CNG}$ e indicando alternativas que, em tese, seriam aquelas adotadas para a pesquisa de delimitação das microrregiões homogêneas. Para tanto, punha-se como necessária a "organização harmoniosa dos diferentes centros do espaço nacional", para que pudessem ser dadas as "bases à planificação econômica" (ROCHEFORT, 1967, p.1/3-4). A racionalização da organização do território se daria exatamente pela definição de regiões homogêneas, nas quais deveria haver uma "semelhança mais ou menos completa das atividades de produção", enquanto extravasariam os limites dessas regiões os espaços polarizados, abarcando "um espaço heterogêneo nas suas atividades de produção, mas dominado pela influência de uma cidade principal, cujo poder de polarização [provocaria] elos de interdependência entre os fragmentos heterogêneos" (ROCHEFORT, 1967, p.2). Na organização do território, deveriam se combinar as regiões homogêneas - mais ligadas a aspectos "naturais" e à atividade agrícola - e as "zonas de centralidade regional", ou o "conjunto do 
espaço dominado pelos fenômenos de centralidade e percorrido pelos fluxos de relação" (ROCHEFORT, 1967, p.2), visando à melhor determinação de áreas "ótimas" para um ponto de partida à organização do território. Essas áreas nada mais seriam que os polos de desenvolvimento à maneira de Perroux.

O IBGE reconhecia os conceitos-chave de polarização e homogeneidade (ou seja, a existência de regiões homogêneas e regiões polarizadas) enquanto fenômenos presentes em intensidades diversas no território brasileiro. Defendia-se o conceito de região homogênea para a Amazônia, diferentemente do Nordeste, Centro-Oeste, Sudeste e Sul, sendo as microrregiões homogêneas os pilares sobre os quais se estruturaria a divisão regional do Brasil. Ao mesmo tempo, identificavam-se polos de crescimento, escolhidos segundo critérios das teorias de Rochefort, hierarquizando as cidades de acordo com a infraestrutura do terciário. Eram destacadas, em $1^{\circ}$ Nível, as metrópoles de Porto Alegre, Curitiba, São Paulo, Rio de Janeiro, Belo Horizonte, Salvador, Recife, Fortaleza e Belém (PEREIRA, et al, 1967, p.84-85), que seriam, aliás, as futuras regiões metropolitanas, instituídas oficialmente pela Lei Complementar $n^{\circ} 14$, de 8 de junho de 1973, tendo sido estabelecida a Região Metropolitana do Rio de Janeiro pela Lei Complementar no 20 , de $1^{\circ}$ de julho de 1974.

Acerca da definição de polos, Pereira et al (1967) diria que:

A seleção dos polos de desenvolvimento partiria de uma distinção fundamental entre centros de polarização (cidades - em vários níveis hierárquicos - capazes de dominar uma região através da extensão de seu setor terciário) e polos de desenvolvimento (locais de expansão de uma atividade, e que necessariamente não precisariam ser, ao mesmo tempo $[\ldots]$ centros de polarização). (PEREIRA et al, 1967, p.86)

A definição dos polos estabelecida pelo IBGE em Esbôço preliminar de divisão do Brasil em espaços homogêneos e espaços polarizados (IBGE, 1967) - documento escrito como auxílio ao Plano Decenal de Desenvolvimento Econômico e Social - seguia, pois, o método de Jean Hautreaux e Michel Rochefort, originalmente concebido para a análise da rede urbana francesa empreendida entre 1963 e 1964 pelo Comissariat Général du Plan - CGP, Escritório Geral de Planejamento, órgão que funcionou entre 1946 e 2006, fundado por De Gaulle, mas cujas origens, remontam - aventando-se uma hipótese, cuja discussão foge ao escopo deste trabalho de que planejamento e autoritarismo caminharam muitas vezes de mãos dadas - ao plano decenal da França de Vichy (governo colaboracionista em relação ao nazismo, o qual tinha à testa o marechal Philippe Pétain) (BERDOULAY; SOUBEYRAN, 2012).

A proposta de Hautreaux e Rochefort centravase na noção de hierarquia geográfica para classificar a rede urbana a partir da importância e intensidade dos fluxos. Em seus estudos, os autores "estabeleceram vinte critérios de fluxos e de equipamentos suscetíveis a caracterizar o nível hierárquico das cidades" (BOUDEVILLE, 1972, p.80). Para cada critério, as cidades receberiam uma nota. Considerando-se os pesos diferentes dos respectivos critérios, as notas ponderadas permitiam ao final classificar as cidades.

No documento em questão (IBGE, 1967), partia-se da classificação dos centros de polarização de acordo com o equipamento terciário polarizador, o qual era relacionado com a atividade industrial e a população urbana do município-polo visando à distinção entre os centros de igual hierarquia.

Com base nas notas obtidas por cada centro, será possível classificá-los segundo o seu 'equipamento terciário polarizador'. Por outro lado, a comparação do nível de equipamento de cada cidade [...] com a atividade industrial aí praticada [...] possibilitará maior distinção entre os centros de nível de equipamento terciário equivalente (CORRÊA; DAVIDOVICH, 1967, p.4).

Como segunda etapa, proceder-se-ia a uma comparação desse equipamento com a população urbana e a atividade industrial de cada cidade ou polo, permitindo estabelecer uma tipologia dos centros de polarização. Essa etapa, certamente a mais complexa, estabeleceria os limites das áreas de alcance de um 
polo, bem como seus níveis, no caso, distribuídos em três hierarquias, baseadas na abrangência espacial da influência dos centros regionais (IBGE, 1967, p.1). Por meio de questionários ( $1^{\mathrm{a}}$ etapa), do levantamento da hierarquia dos polos e de seu campo de influência, chegar-se-ia ao conhecimento das "áreas de atuação dos centros de polarização, através de fluxos de passageiros e de mercadorias; bem como através das relações entre as atividades regionais e os centros de polarização [e de seu respectivo] poder de decisão" (IBGE, 1967, p.5). Em sequência realizar-se-ia a delimitação das áreas, cujo resultado cartográfico seria dado por uma sobreposição de onze cartogramas, seguindo a divisão administrativa estabelecida em 1960, ainda que o estudo se propusesse a revisar os limites das áreas de influência conforme os dados sobre a divisão administrativa do Brasil estivessem atualizados (CORRÊA; DAVIDOVICH, 1967, p.7).

Do "esboço" feito pelo IBGE em 1967 seguiram-se os Subsídios à Regionalização (IBGE, 1968) e a Divisão do Brasil em Micro-Regiões Homogêneas (IBGE, 1970). Esses estudos serviram de apoio para medidas de planejamento público e privado, não apenas durante os anos de 1970, logo após seu aparecimento, mas, vêm sendo usadas com ajustes, inclusive, contemporaneamente, o que pode ser constatado por duas pequenas e óbvias observações. De um lado, o estabelecimento das Grandes Regiões tem sido o mesmo desde então e, por outro, as microrregiões, ainda que tidas como insatisfatórias para a análise das transformações pelas quais o país passou desde a década de 1960 , foram pouco mais que atualizadas - por critérios relacionados à polarização do espaço - nas definições das 558 "microrregiões geográficas", que o IBGE passou a adotar a partir do Censo de 1991: levantamentos censitários, cujo material, ocioso dizer, é, de longe, o mais utilizado e difundido dentre as fontes estatísticas e os dados gerais sobre o Brasil.

Se houve mudanças de critérios para a divisão e subdivisão regionais do Brasil, muitas de suas bases, especialmente aquelas em escala cartográfica mais detalhada, tiveram seus estudos iniciais com os trabalhos realizados pelo IBGE entre o final da década de 1960 e o início da de 1970. Conforme trabalho de Igor Moreira, apresentado durante o III Congresso
Brasileiro de Geógrafos,

A despeito da fraqueza metodológica dos subsídios à regionalização, de Roberto Lobato, o documento do IBGE foi base de trabalhos que buscavam (sem maiores questionamentos) detalhar e dar elementos para sistematização das hierarquias regionais, usando dos mesmos critérios (ensino, serviços de saúde, serviços bancários) [e de cartogramas e métodos de questionários]. (MOREIRA, 1974, p.42).

À parte as conclusões dos próprios técnicos do velho CNG, é imperativo apontar dois dos procedimentos metodológicos adotados no trabalho do IBGE mais passíveis de críticas: o problema dos limites, presos irremediavelmente às jurisdições político-administrativas dos municípios, estados e territórios brasileiros, e a fragilidade da aplicação de questionários, que, meramente recenseando as populações economicamente ativas e/ou o chamado equipamento terciário, não provariam nada "sobre a influência real da cidade sobre a região e, em particular, não [dariam] nenhuma indicação sobre fluxos" que eventualmente ligassem "o espaço regional ao centro" (ROCHEFORT, 1971, p.127-128). Michel Rochefort também estenderia essa admoestação a certas características do estudo sobre a urbanização no Brasil, notadamente em relação à Evolução da rêde urbana brasileira, de Pedro P. Geiger, reconhecendo, porém, a importância dessa obra, publicada alguns anos antes da sistematização da rede urbana feita pelo Conselho Nacional de Geografia - CNG.

Se é significativo observar que o próprio Michel Rochefort fez restrições à forma como o CNG se valeu de seus métodos - além de auto criticá-los em si -, outros autores não se furtaram em ver limitações nos procedimentos em questão. Para um discípulo da teoria dos polos de crescimento de F. Perroux:

A principal reprovação que se pode fazer à classificação de Hautreaux e Rochefort é quanto ao peso arbitrariamente demasiado elevado que atribuem à atividade terciária: os serviços entregues às empresas e aos particulares representam $70 \%$ do peso total dos 
critérios. Trata-se para eles da característica urbana essencial: 'À hierarquia de serviços corresponde uma hierarquia das cidades'. O conjunto dos centros de encadeamento terciário, sobre os quais repousa a vida das relações de uma região, constitui a 'rede urbana' dessa região [...]. Ora, uma cidade não exerce somente uma influência pelos serviços que ela fornece, mas também pelas atividades industriais que ela assume (BOUDEVILLE, 1972, p.80-81. Tradução nossa).

O seminário "A regionalização do espaço no Brasil", realizado em Bordeaux, entre 20 e 22 de novembro de 1968 , elucida bem o balanço teórico necessário, qual seja, o debate em torno dos pontos positivos e negativos dos métodos de regionalização no Brasil, no exato momento no qual a "questão regional" conhecia uma crise em relação à sua eficácia perante a constituição de políticas territoriais. Importante notar também o contexto político em que se via uma possibilidade de transição democrática do regime, em breve sepultada pelo AI-5, ato que "escancarou"de facto a ditadura militar no Brasil (GASPARI, 2002), redefinindo quadros administrativos do país e mesmo posicionamentos político-ideológicos dos membros da burocracia nacional.

Questionava-se a própria validade da existência de regiões nesse conjunto heterogêneo correspondente aos "países subdesenvolvidos". No referido seminário, transcorrido no Centro de Estudos de Geografia Tropical da Faculdade de Letras e Ciências Humanas de Bordeaux, um geógrafo como Bernard Kayser constatava a falta de capacidade de polarização inerente à grande parte dos países subdesenvolvidos: o espaço geográfico nesses países "não é, ou não é completamente, regionalizado", assinalava o autor em trabalho anterior (KAYSER, 1966, p.695). Tomando por base sua tipologia (espaços indiferenciados, regiões de especulação, regiões de intervenção, bacias urbanas e regiões organizadas), Kayser advogaria a tese de um caráter superficial dos fluxos no Brasil, país onde a "estrutura econômica dualista" - com regiões voltadas para fora convivendo com outras de mera subsistência - somente daria margem a uma fraca integração, resultando em um "espaço atomizado".
O autor advogava ainda, que, dadas essas relações espaciais frouxas, em um pretenso processo de indução de polos, haveria enfraquecimento econômico regional em favor da reconcentração dos fluxos econômicos na metrópole nacional (KAYSER, 1971, p.81-82): o que o autor considerava como uma ambiguidade das zonas de influência no Brasil.

Entretanto, a questão mais complexa a ser resolvida na regionalização do espaço no Brasil seria quanto à definição dos limites de uma região. $\mathrm{O}$ ponto de partida para a delimitação das microrregiões era a base jurídica, conforme os três níveis existentes na federação brasileira, adotando-se, no interior de cada estado, critérios os mais variados, desde limites fluviais até rodovias ou entorno de grandes cidades. Destacava-se, portanto, a discussão sobre descentralização e centralização do planejamento. $\mathrm{O}$ atrelamento das microrregiões à superfície jurídica de um país seria algo "mal adaptado à planificação moderna" (KAYSER, 1971, p.83). Em consonância a essa opinião, Pierre George entendia não haver limites,

[...] senão sob a forma de limites convencionais, que são limites da necessidade: fronteiras de Estados e limites administrativos. Cada vez mais se percebe o perigo que apresenta a consagração desses limites [políticoadministrativos] para o desenvolvimento econômico. Limites de necessidade no plano administrativo, eles tornam-se obstáculos ao desenvolvimento se deles se fizer quadros de ação [regiões-programas]. Isto acontece cada vez com mais intensidade, já que a ação se exprime sob a forma de forças - ou de relações de forças - que se projetam sobre o espaço em linha de força e em fluxos cuja intensidade e potência determinam a extensão (GEORGE, 1972, p.9).

Justificando a atuação do Estado na "escolha das localizações" das atividades econômicas, fora da "égide do liberalismo integral", Kayser e George (1980 [1964], p.322) já haviam insistido em uma centralização do planejamento, interpretando "o regionalismo estreito dos grupos de pressão locais" como algo "ultrapassado". Seriam mais "fortes" 
as linhas de força que os limites dos estados e dos municípios, observação que afirmava a centralização do planejamento. Em contraposição, para Lysia Bernardes, esses contornos político-administrativos seriam justificáveis, tendo em vista não prejudicar, numa regionalização em favor do planejamento, os interesses dos estados da federação, "mesmo em um plano de governo federal". Na opinião de Lysia Bernardes,

A subdivisão [regional] dos estados [da federação], mesmo dos menores, se justifica inclusive por uma necessidade de se criar unidades do território, maiores que os municípios e menores que os estados, para uso de estatísticas, tendo por base unidades homogêneas (CNRS, 1971, p.85. Tradução nossa).

No âmbito das restrições de ordem legislativa e constitucional, advindas com o golpe militar, a "questão da federação" (nuclear, aliás, na história brasileira) ganhava uma leitura bastante singular da parte dos seguidores das políticas de planejamento. Os freios postos pelo regime às políticas regionais não coordenadas pela União - a qual ganhou competência, com o inciso 13 do artigo $8^{\circ}$ da Constituição de 1967, para estabelecer e executar planos regionais - jamais foram tratados politicamente. Enfatizando o estudo regional e o trabalho de campo, as argumentações de Kayser e George legitimavam um planejamento centralizado - algo complicado em um país à sombra de um regime militar -, contrariamente à postura a favor de um planejamento em nível regional, preconizada por Lysia Bernardes. Rochefort considerava como uma "necessidade" tentar projetar sobre o espaço brasileiro "o esquema de ordenamento usado nos países desenvolvidos", visando a pesquisar a eventual existência de "regiões orgânicas", ou seja, de "espaços compreendidos nos limites do poder de polarização de um grande centro, cada qual organizado por toda uma rede de centros urbanos, formando o entorno da influência do grande centro" (ROCHEFORT, 1971, p.127). Ademais, constatada a dissimetria entre os centros de $1^{\circ}$ nível, tornava-se difícil rastreá-las no Brasil, haja vista que o conceito deveria supor "a existência de ligações [...] permanentes entre o espaço regional e o grande centro" de comando; não sendo esse o caso "de uma grande parte do espaço brasileiro teoricamente polarizado por uma dessas grandes cidades" (ROCHEFORT, 1971, p.129).

Para Rochefort (1971, p.129-130), na maioria dos casos, as grandes cidades brasileiras não manteriam relações diretas com seu espaço de influência, mas sim, relações tênues, faltando, para uma polarização efetiva, o desenvolvimento econômico, o aumento do poder de compra e a efetiva constituição de mercados consumidores locais de muitas das regiões do Brasil. Esses centros urbanos eram demarcados, aliás, a partir de critérios puramente demográficos, o que resultava em um trabalho insuficiente. Como enriquecimento de sua metodologia, Rochefort propôs (1971, p.133-134) uma tipologia regional heterogênea para o Brasil: ao Sul e ao Sudeste se contrapunha a Amazônia ("setor vazio" e sem organização do espaço) e os "setores de economia tradicional", tanto os de alta ou média densidade demográfica (caso do Nordeste, com a preponderância de Fortaleza, Recife e Salvador), quanto os de baixa densidade, nos quais o papel das cidades seria fraco.

Para Rochefort (1971), São Paulo era de fato a região orgânica do país, núcleo de rede urbana nacional (GEIGER, 1971), opinião partilhada por outros geógrafos, como Pierre George. Na classificação deste último sobre os grandes setores econômicos e sociais do espaço brasileiro (setor vazio - Amazônia; setor de economias tradicionais e fraca densidade demográfica - Nordeste; Região Sudeste e Sul do Brasil [GEORGE, 1971]), o autor considerava a existência de fatores, ligados à economia do café, que adensaram o setor terciário, impulsionando a região Sudeste rumo à industrialização, tornando-a polarizável, capaz, enfim, de conduzir uma rede urbana.

Assim, estavam demarcados no final da década de 1960, seja no Seminário do CNRS, seja na produção do IBGE, os entraves metodológicos que os estudos sobre regionalização teriam de enfrentar caso sua finalidade fosse (e era) a de suprir, fornecendo dados quantificáveis, os escopos do planejamento estatal. No encerramento do Seminário do Centro de Estudos de Geografia Tropical, Olivier Dollfus (1971, p.188) sintetizou os debates ocorridos, reafirmando 
o conceito de regionalização enquanto "ato político visando a melhorar o desenvolvimento econômico [e acompanhado] necessariamente da criação de limites [e] de fronteiras [em seu] interior". O "Nordeste pobre, ainda marcado pela economia colonial, a Amazônia quase vazia e os polos de desenvolvimento modernos que são o Rio de Janeiro e São Paulo" evidenciavam a dualidade do espaço econômico do Brasil, cujos problemas deveriam ser corrigidos mediante uma política focada em uma regionalização em espaços de intervenção do Estado para a aplicação de políticas públicas.

Os atos políticos subsequentes aos trabalhos do IBGE de 1967-68 confirmaram, no encontro entre a geografia regional francesa e os desígnios de um Estado autoritário, o enfraquecimento político da regionalização em favor de uma leitura meramente administrativa da "temática regional". Entretanto, sobretudo após a ascensão de Isaac Kerstenetsky na presidência do IBGE (1970-1979), o órgão encampou as críticas feitas no Seminário de Bordeaux sob a vigência de um projeto de nação cada vez mais voltado para a tecnificação do território. Internamente, a partir de 1970, Speridião Faissol toma a centralidade no Instituto antes creditada a Lysia Bernardes. Sob tal influência e ao lado das limitações dos métodos oriundos da Geografia Ativa, as "soluções" encontradas se aproximariam rapidamente da quantificação e de uma inconteste influência norte-americana na geografia ibegeana e nas pretensões do planejamento: o levantamento cartográfico e a demanda de dados estatísticos, que se tornariam as funções centrais do IBGE. A virada para a década de 1970 demonstrou uma grande mudança na produção do Instituto - e mesmo na produção geográfica brasileira -, marcada, a partir daí, por formulações de autores como Bunge, B. Berry, P. Cole, Harvey, dentre outros.

As mudanças políticas e teóricas no IBGE e o ambiente político da ditadura teriam afastado Michel Rochefort da experiência brasileira, como ele mesmo assim o confirmaria (PUC CAMPINAS, 2006). Mas, não tardaria a retornar para o lado de baixo do Equador, quando, entre 1974 e 1978 (ainda sob a égide do regime militar), envolveu-se com o SERPHAU (Serviço Federal de Habitação e Urbanismo do BNH) e com a Comissão Nacional de Política Urbana (CNPU). Sua herança intelectual permeou a obra, notadamente, de Lysia Bernardes e de Roberto Lobato. Nos anos mais recentes, Maria Adélia A. de Souza tornou-se uma de suas principais discípulas no Brasil.

\section{CONSIDERAÇÕES FINAIS}

As análises do vasto trabalho de Rochefort com planejamento e urbanismo e de seus aspectos teóricometodológicos (certamente desvinculados ao longo dos anos da "Geografia Ativa") vão muito além dos limites deste trabalho. Em que pesem as dificuldades e deficiências da transposição de seu método para o Brasil, e, na realidade, toda a transferência de teorias de planejamento feita pelos planejadores do regime militar - fartamente criticada por Coraggio (1973) e Santos (2003), os quais apontam para o efeito inverso dos polos de desenvolvimento no território, ao reforçar, externamente, o caráter de dependência em relação aos grandes centros econômicos mundiais do capitalismo e, internamente, avigorando a Região Concentrada (SANTOS; SILVEIRA, 2005) -, as propostas de Rochefort, Pierre George, Lacoste, dentre outros, tiveram, também com suas próprias restrições, dada a dubiedade entre o tradicionalismo vidalino e os ares marxistas, importância inequívoca, ao chamar atenção para a dimensão econômica nos processos de regionalização. As propostas da "Geografia Ativa" desses geógrafos, como aqui se procurou evidenciar, gerou, no caso brasileiro, as bases de uma política econômica de amplas e importantes consequências para o país.

Dois pontos para finalizar. Primeiro, os desenvolvimentistas certamente acreditavam no papel do Estado enquanto grande interventor na organização do território, de maneira a corrigir as "inadaptações" da economia capitalista, ainda mais em países "subdesenvolvidos" (ROCHEFORT, et al, 1970). Segundo, conforme o Quadro 1 demonstra, a influência de Rochefort percorreu, tomando como exemplos somente o Boletim Carioca de Geografia e a Revista Brasileira de Geografia, décadas na produção geográfica nacional, afirmando-o como inolvidável na construção do que é hoje a geografia brasileira. 
Quadro 1 - Artigos da Revista Brasileira de Geografia [RBG] e do Boletim Carioca de Geografia [BCG] em que há citações ou menções a Michel Rochefort ou artigos publicados pelo próprio professor.

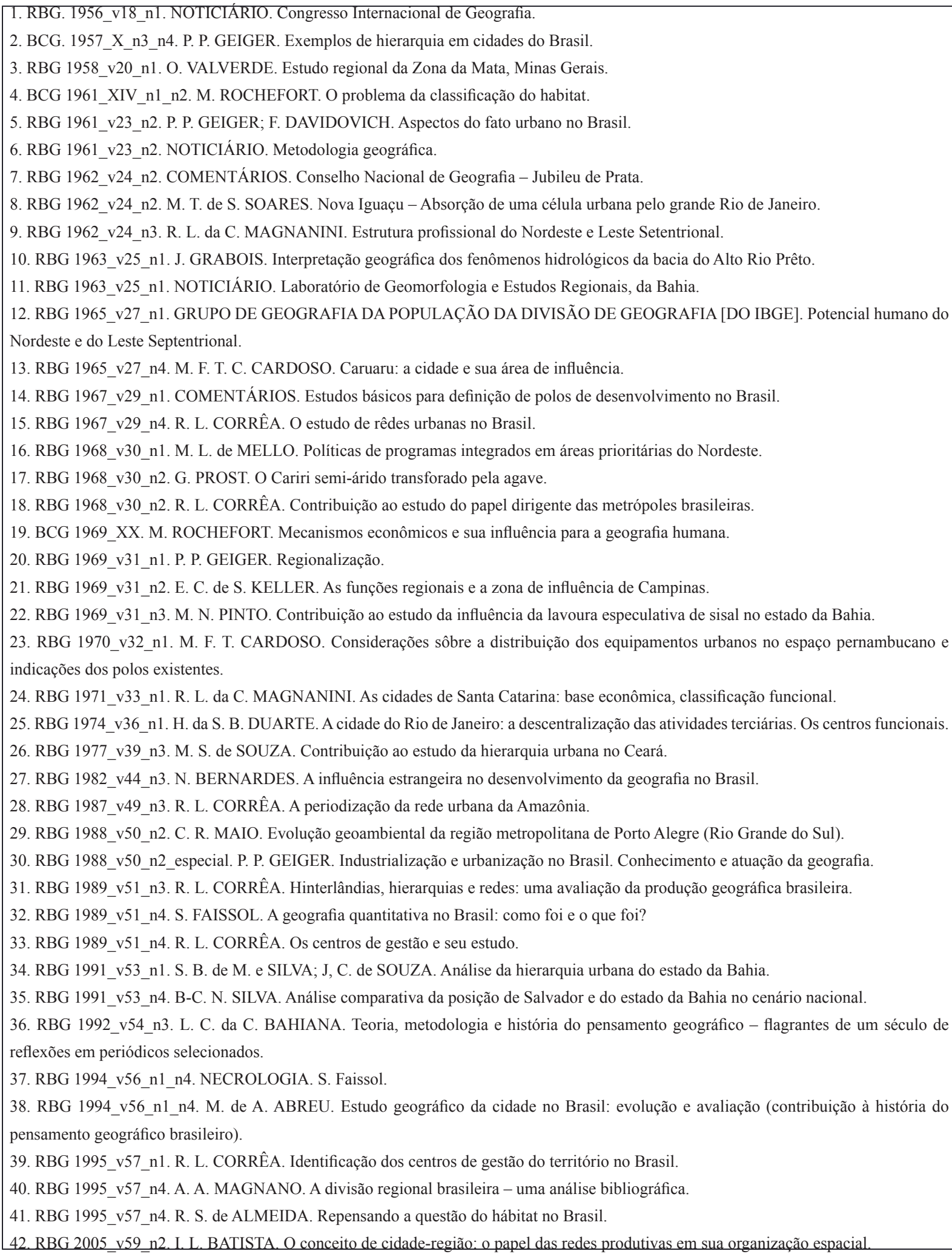




\section{REFERÊNCIAS}

BERDOULAY, V.; SOUBEYRAN, O. Pratiques réflexives en aménagement pour une adaptation aux changements environnementaux. In: L'Espace Géographique. Paris: Belin, 2012, $\mathrm{n}^{\circ}$ 2; tomo 41, pp.169-180.

BERNARDES, L. M. C. (coord.). O Rio de Janeiro e sua região. Rio de Janeiro: IBGE, Conselho Nacional de Geografia, Divisão de Geografia, 1964.

BOUDEVILLE, J-R. Aménagement du territoire et polarisation. Paris: Éditions M.-TH Génin, 1972.

BRASIL. I Plano Nacional de Desenvolvimento (I PND) - 1972/74. Brasília, 1971.

BRASIL. II Plano Nacional de Desenvolvimento (II PND) - 1975/79. Brasília, 1974.

CNRS (Centre d'Études de Géographie Tropicale du Centre National de la Recherche Scientifique). $L a$ régionalisation de l'espace au Brésil. Paris: Éditions du Centre National de la Recherche Scientifique, 1971.

CORAGGiO, J. L. Dos ensayos sobre la teoría de los polos de desarrollo. Buenos Aires: Centro de Estudios Urbanos y Regionales. Instituto Torcuato Di Tella, 1973.

CORRÊA, R. L. Os estudos de rêdes urbanas no Brasil. In: Revista Brasileira de Geografia. Rio de Janeiro, 1967, n. 29, tomo 4, pp.93-116.

CORRÊA, R. L; DAVIDOVICH, F. R. Centros de polarização do Brasil (metodologia adotada). In: Esboço preliminar de divisão do Brasil em espaços homogêneos e espaços polarizados. Rio de Janeiro: IBGE, Conselho Nacional de Geografia, Divisão de Geografia, 1967, pp.1-7.

CORREIA FILHO, V. Conselho Nacional de Geografia - Jubileu de Prata. In: Revista Brasileira de Geografia Revista Brasileira de Geografia. Rio de
Janeiro, 1962, n. 24, tomo 2, pp.285-298.

DOLLFUS, O. Rapport de synthèse. In: CNRS. La régionalisation de l'espace au Brésil. Paris: Éditions du Centre National de la Recherche Scientifique, 1971, pp.185-188.

ESCOLAR, M; MORAES, A. C. R. Pierre George: compromiso político, fragilidad teórica y temática regional. In: Anales del II Encuentro de Geógrafos Latinoamericanos. Montevideo: 1991, pp.173-184.

GASPARI, E. A ditadura escancarada. São Paulo: Companhia das Letras, 2002.

GEIGER, P. P. Exemplos de hierarquia em cidades do Brasil. In: Boletim Carioca de Geografia. Rio de Janeiro: Associação dos Geógrafos Brasileiros, Seção Rio de Janeiro, 1957, Ano X, n. 3 e 4, pp.5-15.

GEIGER, P. P. Evolução da rêde urbana brasileira. Rio de Janeiro: INEP - Instituto Nacional de Estudos Pedagógicos, 1963.

GEIGER, P. P. Les Villes a fonction industrielle et la régionalisation du Brésil. In: CNRS. La régionalisation de l'espace au Brésil. Paris: Éditions du Centre National de la Recherche Scientifique, 1971, pp.146-161.

GEORGE, P. Villes et organisation de l'espace au Brésil. In: CNRS. La régionalisation de l'espace au Brésil. Paris: Éditions du Centre National de la Recherche Scientifique, 1971, pp.136-148.

GEORGE, P. Os métodos da geografia. São Paulo: Difusão Europeia do Livro, 1972.

GRUPO de geografia da população da Divisão de Geografia [IBGE]. Potencial humano do Nordeste e do Leste Septentrional. In: Revista Brasileira de Geografia. Rio de Janeiro, 1965, n. 27, tomo 1, pp.144-164.

IBGE. Esboço preliminar de divisão do Brasil em espaços homogêneos e espaços polarizados. Rio de Janeiro: IBGE, Conselho Nacional de Geografia, 
Divisão de Geografia, 1967.

IBGE. Subsídios à regionalização. Rio de Janeiro: Fundação IBGE, Instituto Brasileiro de Geografia, Divisão de Geografia, 1968.

IBGE. Divisão do Brasil em micro-regiões homogêneas - 1968. Rio de Janeiro: Fundação IBGE, Instituto Brasileiro de Geografia, Divisão de Geografia, 1970. KAYSER, B. Les divisions de l'espace géographique dans les pays sous-développés. In: Annales de Géographie. Paris: Librairie Armand Colin, 1966, LXXV, n. 412, pp.686-697.

KAYSER, B. Les types de région au Brésil. In: CNRS. La régionalisation de l'espace au Brésil. Paris: Éditions du Centre National de la Recherche Scientifique, 1971, pp.75-86.

KAYSER, B; GEORGE, P. A região como objeto de intervenção. In: GEORGE, $\mathrm{P}$, et al. A geografia ativa. $5^{\text {a }}$ ed. São Paulo; Rio de Janeiro: DIFEL, 1980, pp.322-354.

MACHADO, M. S. A geografia universitária carioca e o campo científico-disciplinar da geografia brasileira. São Paulo: Tese de Doutorado. Área de Geografia Humana. Departamento de Geografia. FFLCH, USP, 2002.

MAGNANINI, R. L. da C. Estrutura profissional do Nordeste e Leste Setentrional. In: Revista Brasileira de Geografia. Rio de Janeiro, 1962, n. 24, tomo 3, pp.474-480.

MYRDAL, G. Teoria econômica e regiões subdesenvolvidas. Rio de Janeiro: Sâga, 1965.

MOREIRA, I. A. G. Contribuição ao estudo da função regional de Caxias do Sul: a atuação dos serviços. In: AGB. $3^{\circ}$ Congresso Brasileiro de Geógrafos comunicações. Rio de Janeiro: AGB; FIBGE, 1974, p.42-47.

NOTICIÁRIO. Laboratório de Geomorfologia e Estudos Regionais, da Bahia. In: Revista Brasileira de
Geografia. Rio de Janeiro, IBGE, 1963, n. 25, tomo 1, pp.130-138.

NOTICIÁRIO. Fundação IBGE. In: Revista Brasileira de Geografia. Rio de Janeiro: 1967, n. 29, tomo 3, pp.119-120.

PENHA, E. A. A criação do IBGE no contexto de centralização política do Estado Novo. Rio de Janeiro: Fundação Instituto Brasileiro de Geografia e Estatística, 1993.

PEREIRA, R. de M, et al. Estudos básicos para definição de polos de desenvolvimento no Brasil. In: Revista Brasileira de Geografia. Rio de Janeiro, 1967, n. 29, tomo 1, pp.82-101.

PERROUX, F. A economia do século XX. Lisboa: Herder, 1967.

PONTES, B. S. Brasil: O Estado planejador e as políticas nacionais de urbanização (1937-1979). São Paulo: Tese de Doutorado. Área de Geografia Humana. Departamento de Geografia. FFLCH, USP, 1983.

PUC CAMPINAS. I Encontro Internacional da Extensão e da Pesquisa - A Metrópole e o Futuro (dinâmicas do lugar e metropolização). PUC Campinas: Campinas, 11-13 de setembro de 2006.

ROBIC, M-C., et al. Géogrpahes face au monde. L'Union Géographique Internationale et les congrès internationaux de géographie. Paris; Montréal: L'Harmattan, 1996.

ROCHEFORT M. Determination des types de villes d'un reseau urbain - méthode d'analyse de la population active. In: UGI (Union Géographique Internationale). Les comptes rendus du XVIII ème Congrès International de Géographie. Rio de Janeiro: UGI, Comité du Brésil, 1959, III, pp.426-431.

ROCHEFORT, M.O problema da regionalização no Brasil. Rio de Janeiro: IPEA, 1967.

Soc. \& Nat., Uberlândia, 27 (3): 365-378, set/dez/2015 
ROCHEFORT, M., et al. Aménager le territoire. Paris: Éditions du Seuil, 1970.

ROCHEFORT, M. Villes et organisation de l'espace au Brésil. In : CNRS. La régionalisation de l'espace au Brésil. Paris: Éditions du Centre National de la Recherche Scientifique, 1971, pp.127-135.

SANTOS, M. Economia espacial. $2^{\mathrm{a}}$ ed. São Paulo: Edusp, 2003.

SANTOS, M.; SILVEIRA, M. L. O Brasil: território e sociedade no início do século XXI. $7^{\mathrm{a}}$ ed. Rio de Janeiro; São Paulo: Record, 2005.

UGI (Union Géographique Internationale). Les comptes rendus du XVIII e Congrès International de Géographie. Rio de Janeiro: UGI, Comité du Brésil, 1959. 